LINGUA, Vol. 15, No. 2, September 2018

p ISSN: 1979 9411; e ISSN: 2442 238X

Http://lingua.pusatbahasa.or.id; Email:presslingua@gmail.com

Center of Language and Culture Studies, Surakarta, Indonesia

Suryaningsih, Lili; Rusdiawan \& Nuriadi. 2018. Kajian Makna Nggahi dan Makka

pada Budaya Penyambutan Tamu Tamu Besar di Dompu.

Lingua (2018), 15(2): 83 96. DOI: 10.30957/lingua.v15i2.479.

\title{
KAJIAN MAKNA NGGAHI DANA DAN MAKKA PADA BUDAYA PENYAMBUTAN TAMU-TAMU BESAR DI DOMPU
}

\author{
Lili Suryaningsih, Rusdiawan \& Nuriadi \\ Program Magister Pendidikan Bahasa Indonesia \\ Universitas Mataram \\ Jln. Majapahit No.62 Gomong Kota Mataram \\ Email Korespondensi: liliedaelilu@gmail.com
}

\begin{abstract}
The purposes of this study are to describe the meaning of nggahi funds and makka, a tradition to welcome honored guests in Dompu and to identify meanings in the nggahi and makka in the recent social values. The tradition was derived from the indigenous local cultures that currently was retained as one of the folklore so that the researchers approached using the ethnographic study. Three informants were interviewed, tradition ceremony to welcome guests was observed records were analyzed, and introspection was conducted. Analyses were done based on the verbatim transcripts of the traditions. The study revealed that four symbols apply in the nggahi fund traditions and two in makka having connotative and denotative meaning. Guests are greatly appreciated and served in high honors. Values as the Islamic teaching denote are embedded in the social interations in the nggahi and makka.
\end{abstract}

Keywords: honored guest, tradition, nggahi, makka, tradition.

DOI: 10.30957/lingua.v15i2.479.

\section{PENDAHULUAN}

Bahasa merupakan medium untuk memunculkan arti penting yaitu signifikansi atau makna bahasa. Mengidentifikasi suatu budaya berarti mengeksplorasi makna diproduksi secara simbolik di dalam bahasa sebagai sebuah system tanda. Bahasa bertindak sebagai sarana pemertahanan kebudayaan, sebuah kebudayaan akan mampu dimengerti, dipahami, dan dijunjung oleh penerima budaya jika mereka mengerti bahasa pengantar kebudayaan tersebut. Bahkan sering timbul pendapat bahwa kebudayaan lahir karena bahasa, tanpa bahasa tidak akan pernah ada budaya. Meski begitu ternyata bahasa suatu masyarakat ternyata sangat dipengaruhi oleh kebudayaan masyarakatnya. Bahasa bersifat unik dan mempunyai hubungan yang sangat erat dengan budaya masyarakat pemakainya, maka analisis suatu bahasa hanya berlaku untuk bahasa itu saja, tidak dapat digunakan untuk menganalisis bahasa lain.

Daerah Dompu memiliki kekhasan dalam budaya menyambut tamu-tamu besar dan penyambutan pengantin dalam acara pernikahan, yang diawali oleh salah satu sanggar di Dompu yaitu Sanggar Nggahi Rawi Pahu. Sanggar ini menuangkan ide-ide 
LINGUA, Vol. 15, No. 2, September 2018

p ISSN: 1979 9411; e ISSN: 2442 238X

Http://lingua.pusatbahasa.or.id; Email:presslingua@gmail.com

Center of Language and Culture Studies, Surakarta, Indonesia

Suryaningsih, Lili; Rusdiawan \& Nuriadi. 2018. Kajian Makna Nggahi dan Makka pada Budaya Penyambutan Tamu Tamu Besar di Dompu.

Lingua (2018), 15(2): 83 96. DOI: 10.30957/lingua.v15i2.479.

untuk kegiatan sosial berupa berbagai macam tari. Dan nama sanggar tersebut di ambil dari semboyan Dompu yaitu Nggahi Rawi Pahu yang memiliki arti Ucapan Perbuatan dan Wujud yang berarti semboyang kinerja pemerintah dan masyarakat Dompu dengan tiga langkah yaitu diucapkan, dilakukan dan diwujudkan. Dengan demikian sanggar ini melakukan kegiatan di atas tatanan semboyan atau kaidah kepemerintahan.

Salah satu data yang dijadikan suatu penelitian berasal dari sanggar nggahi rawi pahu yang menjadi kegiatan kelisanan berupa Nggahi Dana dan Maka merupakan suatu tradisi lisan yang digunakan oleh orang Dompu sebagai budaya penerimaan tamu-tamu besar. Nggahi yang berarti bahasa, kata atau ucapan, sedangkan Dana yang berarti tanah jadi nggahi dana dalam ranah konteks bahasa pemerintahan dengan asumsi bahwa Nggahi dana tersebut tidak di artikan secara sempit karena secara logika tidak adannya bahasa tanah namun tanah yang dimaksud adalah pemilik tanah atau penduduk yang berpijak di atas tanah tersebut dengan demikian disebutlah bahasa kepemerintahan atau bahasa masyarakat. Sebagai penguat adalah konteks yang dituturkan atau pembahasan yang ada didalam Nggahi Dana terdapat semboyang yang dijelaskan di atas yaitu nggahi rawi pahu, dan berisi memperkenalkan daerah Dompu. dan Maka yang memiliki arti hentakan, hentakan ini dilihat dari dua sisi yaitu dari bahasa yang diucapkan dan dari gestur tubuh.

Penyambutan tersebut sebelumnya hanya dengan nonverbal dengan menggunakan pari bongi monca (menabur beras kuning) seperti hal yang dilakukan oleh orang Bima sebagai kekhasan Bima Dompu yang terdapat di daerah lain menaburkan bunga. Seiring waktu munculah nggahi dana dan maka karya Sukri yang sering dipanggil dengan nama Seko dalam transkrip pertunjukan nggahi dana dan makka. Masalah dalam penelitian ini terdapat kata-kata yang tidak dapat dipahami oleh generasi muda yaitu makna yang dituangkan dalam pertunjukan tersebut seperti ngamepu dan sambeka terdapat makna simbolik, makna konotasi dan makna denotasi yang ada dalam pertunjukan tersebut. Tradisi lisan pasti akan mengalami perubahan sesuai dengan dinamika kehidupan pengguna budaya. Dari pernyataan tersebut maka dianggap perlu melestarikan tradisi lisan seperti nggahi dana dan makka sesuai dengan maknanya kekayaan budaya Indonesia pada umumnya dan budaya Bima Dompu khususnya dengan demikian untuk mendukung pelestariannya diperluhkan penelitian-penelitian untuk meminimalisirkan kepunahan suatu tradisi lisan. Polemik tidak akan berhenti semasih pengguna budaya masih hidup, dan ini sebagai salah satu cara untuk mempertahankan dan mengebangkan suatu bahasa dan budaya, yang suatu waktu di ancam kepunahannya. sehingga pertunjukan ini menarik untuk di jadikan suatu penelitian.

Untuk panduan penelitian, rumusan masalah dalam bentuk pertanyaan penelitian dirumuskan sebagai berikut:

1) Bagaimanakah makna nggahi dana pada budaya penyambutan tamu-tamu besar di Dompu?

2) Bagaimanakah makna Makka pada budaya penyambutan tamu-tamu besar di Dompu?

\section{LANDASAN TEORI}


LINGUA, Vol. 15, No. 2, September 2018

p ISSN: 1979 9411; e ISSN: 2442 238X

Http://lingua.pusatbahasa.or.id; Email:presslingua@gmail.com

Center of Language and Culture Studies, Surakarta, Indonesia

Suryaningsih, Lili; Rusdiawan \& Nuriadi. 2018. Kajian Makna Nggahi dan Makka

pada Budaya Penyambutan Tamu Tamu Besar di Dompu.

Lingua (2018), 15(2): 83 96. DOI: 10.30957/lingua.v15i2.479.

\subsection{Teori Semiotik}

Secara umum semiotika adalah ilmu tentang tanda. Umberto Eco, ahli semiotika italia menyatakan semiotika adalah "the discipline studying everything which can be used in order to lie, because if something cannot be used to tell a lie, conversely it cannot be used to tell the trhuth; it cannot, in fact be used to tell at all" yang memiliki arti disiplin mempelajari sesuatu yang bisa digunakan untuk berbohong, karena jika sesuatu tidak dapat digunakanan untuk menceritakan kebohonganan sebaliknya tidak dapat digunakanan untuk menceritakan yang sebenarnya; tidak dapat, sebenarnya bisa digunakan untuk menceritakan sama sekali" yang berbeda dengan barthes. Charles Sanders Peirce membentuk model yang menjelaskan unsur-unsur dalam tanda (sign) kemudian menyebutnya dengan triadic model yaitu satu, object, yaitu sesuatu yang dimaksudkan atau dituju oleh sign berupa fisik, tindakan dan ide. Kedua, representament (sign vehicle), yaitu signifier atau bentuk fisik dari sign yang kita terima melalui panca indra dan kita lihat bentuk sebenarnya. Ketiga, interpretant, yaitu signifierd atau makna yang kita buat untuk signifier atau hal yang kita terima.

Pierce kemudian membagi tanda (sign) kedalam 3 jenis adalah (1) sembolic sign, yang menunjukkan bahwa tidak ada kesamaan antara objek dengan apa yang dimaksud (sifnifier dan signified). (2) ivonic sign, yang menunjukkan adannya kesamaan dan kesinambungan antara objek dengan apa yang dimaksud (signifier dan signified). Antara objek dengan apa yang dimaksud dapat dengan jelas terlihat, terdengar, tercium, atau terasa mirip satu sama lain.(3) indexial sign, yang menghubungkan semua unsur tersebut secara tepat waktu atau dengan hubungan sebab-akibat.

Tanda memiliki makna konotatif dan denotatif, kata tanda atau sign merupakan makna yang tidak sama dengan yang terlihat makna konotatif atau implisit memiliki makna yang irisional dan berbeda dengan yang ditangkap. Makna denotatif merupakan makna yang sebenarnya dan sama dengan apa yang terlihat atau makna yang rasional dan logis, sering juga disebut dengan makna yang ada dalam kamus.

Teori semiotik sosial memberikan jalan keluar untuk mengembalikan objek sekaligus pada latar belakang sosial yang menghasilkannya. Dengan asumsi bahwa makna bukanlah milik dirinya sendiri tetapi berasal dari konteks dimana ia di ciptakan dan menentukan sebuah tanda bisa berarti sangat banyak atau sama sekali tidak berarti. suatu bahasa dalam suatu fenomena sosial yang beranjak dari dimensi suatu masyarakat penutur bahasa yang memperhatikan struktur sosial, proses sosial, pesan yang di sampaikan, selain itu ada tiga model dalam model hubungan teks yaitu a) medan, sebagai ciri semantic teks. b) pelaku, yaitu orang-orang yang terlibat dan c) sarana, yaitu ciri-ciri yang diperankan oleh bahasa (Halliday, 1992:16-18; Ratna, 2004:117-119). Model yang ditawarkan oleh Halliday tersebut berfungsi sejajar dengan pelaku, bentuk sejajar dengan sarana dan makna sejajar dengan medan teks sehingga cocok digunakan untuk mengkaji fungsi dan makna nggahi dana dan makka.

\subsection{Teori Budaya}

Sebelum membahas budaya perlu penjelasan folklor sebab folklor sebagai bagian dari suatu budaya menurut (Dananjaya, (2015:132) folklor adalah kelompok orang- 
orang yang memiliki ciri-ciri pengenal kebudayaan yang membedakan dari kelompok lain dan diwariskan secara turun termurun secara lisan yang disertai perbuatan dan sebagai pengingat. (Koentjaraningrat, (2010:18) mendefinisikan folklor adalah bagian budaya yang kolektif yang diciptakan dan disebarkan melalui lisan yang disertai dengan perbuatan atau alat pengingat. Dengan demikian dapat disimpulkan bahwa folklor adalah hasil dari warisan kebudayaan yang disebarkan secara lisan dan tulisan. Baik dilihat dari segi tradisional, anomim, kegunaan, pralogis maupun kolektif. Budaya atau kebudayaan berasal dari bahasa sanskerta yaitu budhayah yang merupakan bentuk jamak dari buddhi (budi atau akal). (Sibrani, (2004:5) mendefinisikan kebudayan merupakan keseluruhan kebiasaan kelompok masyarakat yang tercermin dalam pengetahuan, tindakan dan hasil karya sebagai manusia yang digunakan untuk memahami lingkungannya dan sebagai pedoman tingkah laku dalam mencapai kedamaian hidup.

Selanjutnta, Nilai budaya merupakan konsep-konsep mengenai sesuatu yang ada dalam alam pikiran sebagian besar dari masyarakat yang mereka anggap bernilai, berharga, dan penting dalam hidup sehingga dapat berfungsi sebagai suatu pedoman yang memberi arah dan orientasi pada kehidupan para warga masyarakat (Koentjaraningrat, 2009:153).

Lebih lanjut, nilai budaya bersifat sangat umum, mempunyai ruang lingkup yang sangat luas, dan biasanya sulit diterangkan secara rasional dan nyata. Namun, justru karena sifatnya yang umum, luas, dan tidak kongkret itu, maka nilai-nilai budaya dalam suatu kebudayaan berada dalam daerah emosional dari alam jiwa para individu yang menjadi warga dan kebudayaan bersangkutan. Selain itu, para individu tersebut sejak kecil telah diresapi dengan nilai budaya yang hidup dalam masyarakatnya sehingga konsep-konsep itu sejak lama telah berakar dalam alam jiwa mereka. Itulah sebabnya nilai-nilai budaya dalam suatu kebudayaan tidak dapat diganti dengan nilai-nilai budaya yang lain dalam waktu singkat.

Sama halnya dengan Suriasumantri (2007:262), menurutnya, nilai-nilai budaya adalah jiwa dari kebudayaan dan menjadi dasar dari segenap wujud kebudayaan. Salah satu wujud kebudayaan adalah tata hidup. Tata hidup berkaitan dengan kegiatan kongkret dari nilai budaya yang bersifat abstrak. Dalam kalimat lain, kegiatan manusia dapat ditangkap oleh pancaindera sedangkan nilai budaya hanya tertangguk oleh budi manusia.

Menurut Kluckhohn (Koentjaraningrat, 2009:154), beberapa masalah dasar dalam kehidupan manusia yang menjadi landasan bagi kerangka variasi sistem nilai budaya adalah, (1) Masalah hakikat dari hidup manusia, (2) Masalah hakikat dari karya manusia, (3) Masalah hakikat dari kedudukan manusia dalam ruang waktu, (4) Masalah hakikat dari hubungan manusia dengan alam sekitarnya. (5) Masalah hakikat dari hubunga manusia dengan sesamanya.

Berikut tabel kerangka Kluckhohn mengenai lima masalah dasar dalam hidup yang menentukan orientasi nilai budaya manusia. (Tabel 1). 
LINGUA, Vol. 15, No. 2, September 2018

p ISSN: 1979 9411; e ISSN: 2442 238X

Http://lingua.pusatbahasa.or.id; Email: presslingua@gmail.com

Center of Language and Culture Studies, Surakarta, Indonesia

Suryaningsih, Lili; Rusdiawan \& Nuriadi. 2018. Kajian Makna Nggahi dan Makka

pada Budaya Penyambutan Tamu Tamu Besar di Dompu.

Lingua (2018), 15(2): 83 96. DOI: 10.30957/lingua.v15i2.479.

Tabel 1. Kerangka Kluckhohn: lima masalah dasar dalam orientasi budaya

(Koentjaraningrat,2009:157)

\begin{tabular}{|c|c|c|c|}
\hline $\begin{array}{l}\text { Masalah Dasar dalam } \\
\text { Hidup }\end{array}$ & \multicolumn{3}{|c|}{ Orientasi Nilai Budaya } \\
\hline Hakikat Hidup & Hidup itu buruk & Hidup itu baik & $\begin{array}{l}\text { Hidup itu buruk, tetapi } \\
\text { manusia wajib berikhtiar } \\
\text { supaya hidup itu menjadi } \\
\text { lebih baik }\end{array}$ \\
\hline Hakikat Karya & $\begin{array}{l}\text { Karya itu untuk } \\
\text { nafkah hidup }\end{array}$ & $\begin{array}{l}\text { Karya itu untuk } \\
\text { kedudukan, kehormatan, } \\
\text { dsb. }\end{array}$ & $\begin{array}{l}\text { Karya itu untuk } \\
\text { menambah karya }\end{array}$ \\
\hline $\begin{array}{l}\text { Persepsi manusia } \\
\text { tentang waktu }\end{array}$ & Orientasi ke masa kini & Orientasi ke masa lalu & Orientasi ke masa depan \\
\hline $\begin{array}{l}\text { Pandangan manusia } \\
\text { tehadap alam }\end{array}$ & $\begin{array}{lr}\text { Manusia } & \text { tunduk } \\
\text { kepada alam } & \text { yang } \\
\text { dahsyat } & \end{array}$ & $\begin{array}{l}\text { Manusia menjaga } \\
\text { keselarasan dengan alam }\end{array}$ & $\begin{array}{l}\text { Manusia berusaha } \\
\text { menguasai alam }\end{array}$ \\
\hline $\begin{array}{lr}\text { Hakikat } & \text { hubungan } \\
\text { manusia } & \text { tehadap } \\
\text { sesamanya } & \end{array}$ & $\begin{array}{lr}\text { Orientasi } & \text { kolateral } \\
\text { (horizontal), rasa } \\
\text { ketergantungan } \\
\text { kepada } \\
\text { (berjiwa } \\
\text { royong) }\end{array}$ & $\begin{array}{l}\text { Orientasi vertical, rasa } \\
\text { ketergantungan kepada } \\
\text { tokoh-tokoh atasan dan } \\
\text { berpangkat }\end{array}$ & $\begin{array}{lr}\text { Individualisme } & \text { menilai } \\
\text { tinggi usaha } & \text { atas } \\
\text { kekuatan sendiri } & \end{array}$ \\
\hline
\end{tabular}

\subsection{Teori Linguistik dan Kebudayaan}

Linguistik kebudayaan merupakan bidang ilmu yang interdisipliner yang mempelajari hubungan antara bahasa dan budaya di dalam suatu masyarakat dan memandang bahasa dan kebudayaan bagaikan dua sisi mata uang yang tidak mungkin ada tanpa yang lainnya. Dikatakan demikian sebab bahasa dari perpektif antropologi merupakan bagian dari kebudayaan sebagaimana yang dijelaskan (Koentjaraningrat, (2009:28) budaya diwariskan secara lebih seksama melalui bahasa dalam artian bahasa pada umumnya sebagai wahana bagi pewarisnya sekaligus pengembangan budaya. Duranti, (1997:27) Menegaskan bahwa mendeskripsikan suatu budaya sama halnya dengan mendeskripsikan bahasa. Foley, (1997:3) berpendapat "anthropological linguistic is the subfield of linguistics" menurutnya linguistik antropologi memandang dan mengkaji bahasa dari sudut pandang antropologi budaya dan bahasa untuk menemukan makna dibalik pemakaiannya.

Palmer (1996) dalam Sukri dan Rusdiawan, (2008:53) Mengatakan bahwa imajeri tidak menjelaskan segala sesuatu tentang bahasa, tetapi penelitian terhadap perannya menerangi banyak penggunaan dalam bidang bahasa dan penelitian tentang banyak penggunaan dan bidang bahasa yang menarik minat para pakar antropologi. Lebih jelas Plamer menjelaskan esensi imejeri bahasa memberikan dasar untuk mengkaji topictopik linguistic pada narasi bahasa kias, semantik kata dan kontruksi gramatikal bahkan pada fonologi didengar sebagai gambar verbal yang tersusun secara kompleks kemudian memperoleh suatu makna yang berkaitan dengan skema imajeri dan suatu pandangan dunia. 


\section{METODE}

\subsection{Jenis Penelitian}

Penelitian ini berdasarkan tujuan tergolong penelitian dasar dengan penelitian kualititatif. Jenis penelitian ini adalah etnografi. Penelitian ini berdasarkan metode yang digunakan tergolong kualitatif interaktif yang menggunakan teknik tatap muka (face to face interaction) untuk mengumpulkan data.

\subsection{Informan}

Penentuan informan pada setiap daerah pengamatan dibutuhkan paling sedikit tiga orang informan dan tiga informan itu ditentukan satu orang informan utama, sedangkan yang lainya sebagai informan pendamping.

\subsection{Teknik Pengumpulan Data}

Untuk memperoleh data yang memadai dalam penelitian ini, ditetapkan tiga metode pengumpulan data yaitu (1) metode simak (pengamatan, observasi), (2) metode cakap (wawancara) dan (metode) intropeksi (Mahsun, 2012:92) berikut akan dijelaskan hakikat dari metode-metode tersebut.

\subsubsection{Metode Simak}

Metode simak adalah metode yang digunakan untuk memperoleh data dengan melakukan penyimakan terhadap penutur kapatu. Metode ini memiliki teknik dasar yang berwujud teknik sadap. Teknik sadap disebut sebagai teknik dasar dalam metode simak karena pada hakikatnya penyimakan diwujudkan dengan penyadapan, dalam artian penelitian dalam upaya mendapatkan data dilakukan dengan menyadap penutur kapatu atau beberapa yang menjadi informan. Dalam praktik ini selanjutnya, teknik sadap ini diikuti dengan teknik lanjutan yang berupa:

\section{1) Teknik simak libat cakap}

Pada teknik ini, penyadapan dengan berpatisipan sambil menyimak, berpartisipan dalam pembicaraan dalam pembiaraan dan menyimak para informan, dalam hal ini, peneliti terlibat langsung dalam dialog.

\section{2) Teknik catat}

Teknik catat ini merupakan teknik lanjutan yang dilakukan ketika menerapkan metode simak dengan teknik lanjutan (teknik simak libat cakap dan teknik simak bebas) yaitu mencatat data yang diperoleh dari informan ke dalam kartu data.

\section{3) Teknik rekam}

Pada teknik ini, peneliti melakukan perekaman terhadap data-data, yang diperoleh dari informan. 
LINGUA, Vol. 15, No. 2, September 2018

p ISSN: 1979 9411; e ISSN: 2442 238X

Http://lingua.pusatbahasa.or.id; Email:presslingua@gmail.com

Center of Language and Culture Studies, Surakarta, Indonesia

Suryaningsih, Lili; Rusdiawan \& Nuriadi. 2018. Kajian Makna Nggahi dan Makka

pada Budaya Penyambutan Tamu Tamu Besar di Dompu.

Lingua (2018), 15(2): 83 96. DOI: 10.30957/lingua.v15i2.479.

\subsubsection{Metode Cakap}

Metode ini disebut metode cakap karena cara yang ditempuh dalam pengumpulan data adalah melakukan perakapan dengan para informan. Metode cakap memiliki teknik dasar berupa teknik pancing yang diikuti dengan teknik lanjutan yaitu teknik cakap semuka. Pada teknik akap semuka ini, peneliti langsung melakukan perakapan dengan pematu sebagai informan dengan sumber pada pancingan yang sudah disiapkan(berupa daftar pertanyaan) atau secara spontanitas. Maksudnya pancingan dapat muncul ditengah-tengah percakapan. Ada beberapa teknik yang peneliti gunakan dalam memancing data yang diharapkan dan informanya yaitu.

1) Teknik lanjutan bawahan lesap

Dalam pelaksanaannya, teknik ini mengaharuskan hadir satu bentuk pancingan. Kemudian, dari bentuk itu dicoba dikembangkan bentuk baru dengan menghilangkan unsur-unsur yang menjadi objek sasaran penelitian. Data yang muncul dari teknik ini berupa data sandingan dari data awal yang dimunculkan sebagai data pijakan. Jadi, pada hakikatnya ini jika telah tersedia data awal dan data awal telah muncul karena pertanyaan peneliti atau muncul secara tidak sadar dari informan.

\section{2) Teknik Lanjutan Bawahan Ganti}

Teknik ganti ini dimaksudkan sebagai salah satu penyediaan data yang dilakukan dengan cara memancing kreativitas informan secara tidak sadar maupun pancingan peneliti. Penggunaan teknik ini dimaksudkan untuk menyediakan data bagi kadar kesamaan.

\section{3) Teknik Lanjutan Bawahan Perluas}

Teknik ini, seperti halnya kedua teknik sebelumnya hanya saja bedanya, teknik ini terutama digunakan untuk menyediakan data analisis bentuk, fungsi dan makna yang menjadi objek sasaran. Caranya, berdasarkan data awal itu peneliti meminta informan untuk menemukan bentuk fungsi dan makna atau informan yang sama dengan bentuk sandingnya.

\subsubsection{Metode Intropeksi}

Metode lain selain metode simak dan cakap yang digunakan dalam penyediaan data adalah metode intropeksi. Sudaryanto (dalam Mahsun, 2012: 102) mengklarifikasikan metode ini sebagai metode analisis data, atau yang disebut sebagai metode refleksif-intropektif, yaitu upaya melibatkan atau memanfaatkan sepenuhpenuhnya, secara optimal peran peneliti sebagai penutur bahasa tanpa melebur lenyapkan peran penelitian itu.

Metode intropeksi adalah metode penyediaan data dengan memanfaatkan intusi kebahasaan peneliti bahasa yang dikuasainya (bahasa ibu). Untuk menyediakan data yang diperlukan bagi analisis sesuai sesuai dengan tujuan penelitianya. Metode ini digunakan untuk mengecek kevalidan data informan. Oleh karena itu, jika terdapat data 
yang meragukan, akan cepat dikenali berdasarkan intuisi kebahasaan yang dimiliki oleh peneliti karena di dalam hal ini peneliti adalah penutur bahasa Mbojo.

\subsection{Teknik Analisis Data}

Dalam analisis data menggunakan rambu-rambu data yang di buat berdasarkan masalah dan tujuan penelitian. Hal ini dilakukan untuk membantu dalam interpretasi dan penafsiran terhadap data penelitian. Hal ini sesuai dengan rancangan penelitian kualitatif yang bersifat deskriptif. Dalam teknik analisis data ini, akan digunakan metode pada teknik referensial dan translasional serta metode distribusional teknik interupsi (sisip). Teknik referensial digunakan dalam upaya menjelaskan makna nggahi dana dan makka.

\section{HASIL DAN BAHASAN}

Nggahi dana dan Makka Dompu dianggap sebagai budaya untuk melestarikan sastra lisan yang ada di daerah Dompu yang di pertunjukkan pada saat penerimaan tamu-tamu besar dan seiring berkembangnya digunakan dalam acara pernikahan, yang di iringi oleh tari pada saat pertunjukan tersebut dan menggunakan gendang khas Bima dan Dompu. data yang yang disajikan ini adalah berupa transkrip yang didengarkan secara berulang-ulang dan mencatatat dan mengumpulkan makna dan fungsi dari informan inti atau penggelut adat dan informan tambahan orang Dompu asli atau orang tua yang mengetahui. Peneliti sebagai partisipan dan data dan analisis nggahi dana dan maka di analisis sebagai berikut;

\subsection{Makna Simbolik}

Pada data nggahi dana terdapat simbol yang kemudian data ini di singkat dengan MSP21 (Makna Simbolik Penanda Petanda, 1 adalah nomor data) Sampai seterusnya yaitu sebagai berikut:

\section{$\underline{\text { Kiri... maimu ita doho kaso }}$}

\section{MSP2.1}

Dalam data nggahi dana terdapat makna simbol kiri yang artinya kiri dengan asumsi makna yang diasosiasikan dengan hal yang kita terima yaitu seperti pada penggunaan kiri! pada saat memberhentikan mobil yang memiliki makna berhenti. Kiri pada teks ini diasumsikan dengan berhenti lalu berjalan pelan-pelan atau berhati-hati dan memiliki makna selamat. kiri sebagai penanda sedangkan selamat sebagai petanda. Dan terdapat simbolik kaso yang artinya kasur dan jika di padukan dengan kata doho maka menunjukkan banyak yang datang atau tamu sekalian dan kata tersebut digunakan pada acara formal dalam bahasa daerah. Kaso sebagai penanda dan sekalian sebagai petanda.

\section{Busi kasisopu marada oi}


Dalam data nggahi dana pada bait ketiga dan baris kedua terdapat makna simbol marada oi yang artinya bagaikan air dengan makna yang di asosiasikan dengan kesejukan. Marada oi sebagai penanda dan kesejukan sebagai petanda dengan harapan dapat menyejukkan tamu yang datang atau sebaliknya.

Miu ra ngamepu marada mina

\section{MSP2.3}

Dalam data nggahi dana pada bait ketiga baris ketiga terdapat makna simbol marada mina yang artinya bagaikan minyak dengan makna yang di asosiasikan dengan melicinkan/melancarkan. Marada mina sebagai penanda dan selembut sebagai petanda dengan harapan dapat melancarkan kegiatan penyambutan berkenaan dengan penyambutan tamu.

\section{Neora kebapu marada wolo}

MSP2.4

Dalam data nggahi dana pada bait ketiga baris keempat terdapat simbol marada Wolo yang artinya bagaikan kapas dengan makna yang diasosiasikan dengan meringankan. Marada wolo sebagai penanda dan meringankan sebagai petanda dengan harapan dapat meringankan pada saat prosesi penyambutan tamu dan sebaliknya.

Pada data Makka selanjutnya akan disingkat menjadi MSM.1 sampai seterusnya sebagai berikut:

\section{Tas rumae...}

\section{MSM.1}

Dalam data Makka terdapat simbol tas rumae yang memiliki dua arti yaitu tas Allah, dan tas Tamu besar, juga di artikan sebagai hentakan dengan nada tinggi sebagai wujud sambutan kegembiraan dan tidak bermakna dalam sebuah kata hanya dilihat dari segi konteks ujaran. tas rumae sebagai penanda dan tamu besar sebagai petanda dengan harapan dapat membuka penyambutan dengan penuh kegembiraan atau semangat.

Ma nggahi rawi pahu
Pahu dei maiba rawi
Rawi dei maiba pahu
Pahu ma ka sahana tangara

\section{MSM.2}

Dalam data makka terdapat kata pahu yang memiliki arti wajah/muka pada baris tiga sampai enam terdapat kesamaan kata pahu dan memiliki arti sesuai konteksnya pada baris ke tiga pahu yang memiliki arti bukti, pahu pada baris keempat memiliki arti yang diperbuat pada baris kelima artinya perbuatan. 


\title{
4.2. Makna Denotasi dan Konotasi
}

Data Informan 1

\section{NGGAHI DANA (TANAH BERPATI)}

Kiri... maimu ita doho kaso

Mu wa'u podajar mai tiomu rasa la mada doho ma da patu ra ambi

Tonda weamu nganto

Doho kaimu wohana

Duduk di tengah

Ngge'e ra mori la mada doho di hela fu'u jago di wombo kancale hala

Kiri maimu ita doho kaso

Busi ra kasisopu marada mina

Neo ra kebapu marada wolo

Sambeka... dodo ku...

Dari data informan $1 \mathrm{di}$ atas terdapat makna denotasi perbaris yaitu Kiri... maimu ita doho kaso "Selamat datang tamu sekalian", Mu wa'u podajar mai tiomu rasa la mada doho ma da patu ra ambi. "Telah benar-benar datang melihat kampung kita yang tidak patut dan layak" Tonda weamu nganto "Jalan di pinggir"Doho kaimu wohana. "Duduk di tengah"Kiri maimu ita doho kaso "Selamat datang tamu sekalian" Ngge'e ra mori la mada doho di hela fu'u jago di wombo kancale hala 'Tempat dan hidup kita disela pohon jagung dikolom gumpalan labu" Kiri maimu ita doho kaso "Selamat datang tamu sekalian"Busi ra kasisopu marada mina "Dingin dan sejuk bagai minyak" Neora kebapu marada wolo "Ringan dan bagaikan kapas" Sambeka... dodo ku... "Silahkan... mari silahkan...". Makna konotatif nggahi dana adalah menyambut kedatangan tamu-tamu besar.

\author{
MAKKA (HENTAKAN) \\ Tas Rumae... \\ Ake La mada doho dou Dompu \\ Ma nggahi rawi pahu \\ Pahu dei maiba rawi \\ Rawi dei maiba pahu \\ Pahu ma kasahana tangara \\ Tas Rumae... \\ Tas Rumae...
}

Dari data maka terdapat makna denotasi Tas Rumae... "silahkan tamu..." Ake La mada doho dou Dompu "Ini kita orang Dompu" Ma nggahi rawi pahu "Yang bicara 
disertai bukti" Pahu dei maiba rawi "bukti penuh bekerja"Rawi dei maiba pahu "Bekerja penuh bukti" Pahu ma kasahana tangara "bukti yang mengsyahkan penamaan" Tas Rumae... "Silahkan tamu..." Tas Rumae... "Silahkan tamu”. Makna konotatif pada makka adalah menjamin keamanan tamu selama berada di Dompu.

Data Informan 2

\title{
NGGAHI DANA (BAHASA MASYARAKAT)
}

Kiri... maimu ita doho kaso

Mu wa'u podajar mai tiomu rasa la mada doho ma da patu ra ambi

Tonda weamu nganto

Doho kaimu wohana

Duduk di tengah

Ngge'e ra mori la mada doho di hela fu'u jago di wombo kancale hala

Kiri maimu ita doho kaso

Busi ra kasisopu marada mina

Neo ra kebapu marada wolo

Sambeka... dodo ku...

Dari data informan 2 makna denotasi yang dituangkan perbaris yaitu Kiri... maimu ita doho kaso, "Selamat datang yang terhormat" $M u$ wa'u podajar mai tiomu rasa la mada doho ma da patu ra ambi "Telah datang di tempat kami yang tidak patut dan layak" Tonda weamu nganto "Melangkah di sudut" Doho kaimu wohana "Duduk di tengah" Kiri maimu ita doho kaso "Selamat datang yang terhormat" Ngge'e ra mori la mada doho di hela fu'u jago di wombo kancale hala "Kehidupan kami di antara dua pohon jagung dan labu" Kiri maimu ita doho kaso "Selamat datang yang terhormat" Busi ra kasisopu marada mina "Dingin dan sejuk serupa minyak" Neo ra kebapu marada wolo "Ringan serupa kapas" Sambeka... dodo ku... "Silahkan... mari menunduk...". Dari data Nggahi Dana makna konotatif yang terdapat informan 2 yaitu menyambut kedatangan tamu sekaligus untuk mengenalkan daerah Dompu dari segi tempat dan harapan akan kesejukan, kenyamanan yang dirasakan oleh tamu.

\author{
MAKA (HENTAKAN) \\ Tas Rumae... \\ Ake La mada doho dou Dompu \\ Ma nggahi rawi pahu \\ Pahu dei maiba rawi \\ Rawi dei maiba pahu \\ Pahu ma kasahana tangara \\ Tas Rumae...
}




\section{Tas Rumae...}

Dari data maka informan 2 makna perbarisnya bermakna Tas Rumae..."(Gembira) tamu besar" Ake La mada doho dou Dompu "Inilah kami orang Dompu" Ma nggahi rawi pahu "Yang berbicara disertai perbuatan" Pahu dei maiba rawi "Bukti bukan prioritas dalam bekerja" Rawi dei maiba pahu "Bekerj menjadi prioritas bukti" Pahu ma kasahana tangara "Wajah yang mengsahkan nama” Tas Rumae... "(Gembira) tamu besar" Tas Rumae... "(Gembira) tamu besar" makna konotatif pada informan 2 yaitu untuk menunjukan orang Dompu yang taat akan pekerjaan, tidak hanya ngomong saja tapi perkataan yang disertai perbuatan dan penuh bukti. Mengajarkan tentang karakter yang perluh dicontoh.

Data informan 3

\section{NGGAHI DANA (BAHASA)}

Kiri... maimu ita doho kaso

Mu wa'u podajar mai tiomu rasa la mada doho ma da patu ra ambi

Tonda weamu nganto

Doho kaimu wohana

Duduk di tengah

Ngge'e ra mori la mada doho di hela fu'u jago di wombo kancale hala

Kiri maimu ita doho kaso

Busi ra kasisopu marada mina

Neo ra kebapu marada wolo

Sambeka... dodo ku...

Pada data 3 terdapat makna yang disajikan perbaris adalah Kiri... maimu ita doho kaso "Yang terhormat,Selamat datang tamu besar (penjelasanya sesuai konteks siapa yang datang)" $М u$ wa'u podajar mai tiomu rasa la mada doho ma da patu ra ambi"Telah datang tamuku, Inilah kampung kami yang sederhana" Tonda weamu nganto "Berhati-hatilah" Doho kaimu wohana "Berkumpul dan singgahlah" Kiri maimu ita doho kaso "Yang terhormat, Selamat datang tamu besar" Ngge'e ra mori la mada doho di hela fu'u jago di wombo kancale hala "Kehidupan kami yang sesederhana ini (historis peningkatan ekonomi masyarakat Dompu oleh Bupati program jagung (umumnya pertanian))" Kiri maimu ita doho kaso "Yang terhormat, Selamat datang tamu besar" Busi ra kasisopu marada mina "Kebetahan yang diharapkan oleh kami" Neo ra kebapu marada wolo "Senantiasa diberi kehangatan dan kesehatan" Sambeka... dodo ku... " Mari menghormat (serupa hormat orang cina menundukkan setengah tubuh dan serupa santabe bagi orang Bima tabe bagi orang Lombok)". Makna konotatif nggahi Dana adalah sebagai penyambutan tamu-tamu besar, sebagai penanda penyambutan hangat dari masyarakat maupun istitusi dan lain-lain sebagai bentuk rasa tanggung jawab agar tamu dapat merasakan kenyamanan selama berada di Dompu, 
sebagai bentuk suguhan menikmati suasana yang disajikan berbagai elemen-elemen, sebagai tanda rendah hati dengan kesederhanaan

\author{
MAKA (HENTAKAN) \\ Tas Rumae... \\ Ake La mada doho dou Dompu \\ Ma nggahi rawi pahu \\ Pahu dei maiba rawi \\ Rawi dei maiba pahu \\ Pahu ma kasahana tangara \\ Tas Rumae... \\ Tas Rumae...
}

Pada data maka informan 3 terdapat makna perbaris adalah Tas Rumae... "Tas (hentakan pertanda acara di mulai/nada kegembiraan akan mulainya acara/sambutan) tamu besar..."Ake La mada doho dou Dompu "Inilah kami orang Dompu” Ma nggahi rawi pahu "Yang mengerjakan sesuatu disertai perbuatan dan penuh bukti" Pahu dei maiba rawi "Pembuktian mengalahkan pekerjaan (hasil yang sempurna)" Rawi dei maiba pahu "Perbuatan disertai bukti" Pahu ma kasahana tangara "Bukti yang mengangkat nama Dompu” Tas Rumae... "Tas (hentakan pertanda acara di mulai/nada kegembiraan akan mulainya acara/sambutan) tamu besar..." Tas Rumae... "Tas (hentakan pertanda acara di mulai/nada kegembiraan akan mulainya acara/sambutan) tamu besar..." makna konotatif dari data makka informan 3 adalah untuk menjamin keamanan tamu selama berada di Dompu.

\title{
5. SIMPULAN
}

Berdasarkan pembahasan kajian pertunjukan nggahi dana dan makka dapat simpulkan bahwa terdapat empat makna simbolik pada transkrip nggahi dana dan terdapat dua makna simbolik pada transkrip makka. Makna denotatif atau makna sebenarnya dan sama dengan makna yang terlihat atau makna yang rasional dan logis dan makna konotatif dari tanda sesuatu yang cenderung bersifat implisit atau memiliki makna yang rasional dan berbeda dengan apa yang ditangkap. Makna denotatif yang terdapat pada nggahi dana adalah "Yang terhormat, Selamat datang tamu besar (penjelasanya sesuai konteks siapa yang datang)" "Telah datang tamuku, Inilah kampung kami yang sederhana" "Berhati-hatilah" "Berkumpul dan singgahlah" "Yang terhormat, Selamat datang tamu besar" "Kehidupan kami yang sesederhana ini (historis peningkatan ekonomi masyarakat Dompu oleh Bupati program jagung (umumnya pertanian))" "Yang terhormat, Selamat datang tamu besar" "Kebetahan yang diharapkan oleh kami" "Senantiasa diberi kehangatan dan kesehatan" " Mari menghormat (serupa hormat orang cina menundukkan setengah tubuh dan serupa santabe bagi orang Bima tabe bagi orang Lombok)". Makna denotatif yang terdapat pada makka adalah "Tas (hentakan pertanda acara di mulai/nada kegembiraan akan mulainya acara/sambutan) 
tamu besar..." "Inilah kami orang Dompu" "Yang mengerjakan sesuatu disertai perbuatan dan penuh bukti"'"Pembuktian mengalahkan pekerjaan (hasil yang sempurna)"“Perbuatan disertai bukti"“" Bukti yang mengangkat nama Dompu" "Tas (hentakan pertanda acara di mulai/nada kegembiraan akan mulainya acara/sambutan) tamu besar..." Tas (hentakan pertanda acara di mulai/nada kegembiraan akan mulainya acara/sambutan) tamu besar..." Makna konotatif yang terdapat pada nggahi dana adalah penyambutan kedatangan tamu-tamu besar dan Makna konotatif yang terdapat pada makka adalah menjamin keselamatan dan keamanan tamu selama ia berada di daerah Dompu.

\section{DAFTAR PUSTAKA}

Barthes, Roland. 1972. Membedah Mitos-Mitos Budaya Massa. Jakarta: Jalasutra

Barthes, Roland.2012. Elemen-Elemen Semiotika. Terjemahan M. Ardiansyah. Jokjakarta: IRCiSoD

Danandjaja, James.1997. Foklor Indonesia: Ilmu Gosip, Dongeng dan lain-lain. Jakarta: Graviti.

Duranti, Alessandro.1997. Linguistic Anthropology. Cambridge: University Press.

Foley, William A.1997. Anthropological Linguistic. An Introduction Oxford: Blackwell Publishers.

Halliday, M.A.K.1997. Exploration in The Funcional Of Languange. New Jersey: Lawrence Erlbaum Anold Ltd.

Koentjaraningrat. 2009. Pengantar Ilmu Antropologi. Jakarta: Rineka Cipta.

Koetjaningrat.1975. Manusia dan Kebudayaan di Indonesia. Jakarta: Penerbit Djambatan.

Koetjaningrat. 2009. Pengantar Ilmu Antropologi. Jakarta : PT Rineka Cipta.

Mahsun. 2012. Metode Penelitian Bahasa: Tahapan Strategi, Metode, dan Tekniknya. Jakarta: Rajawali Pers

Piliang, Yasraf A. 2003. Hipersemiotika Tafsir Cultural Studies Atas Matinya Makna.Yogyakarta: Jalasutra.

Sibrani, Robert.2004. Antropolinguistik.Medan: Poda.

Sukri dan Rusdiawan.2008. Bahasa Dalam Realitas Sosial Memahami Kenyataan Bahasa Dalam Dinamika Kemasyarakatan. Mataram: Cerdas Press.

Suriasumantri, Jujun S. 2007. Filsafat Ilmu. Jakarta: Pustaka Sinar Harapan. 